La Revue

des Droits

de l'Homme

\section{La Revue des droits de l'homme}

Revue du Centre de recherches et d'études sur les droits fondamentaux

Actualités Droits-Libertés | 2011

CHARTE DES DROITS FONDAMENTAUX DE L'UNION EUROPEENE (UE)

\title{
Premier rapport annuel de la Commission européenne
}

CHARTE DES DROITS FONDAMENTAUX DE L'UNION EUROPEENE

\section{Sylvia Preuss-Laussinotte}

\section{OpenEdition}

Journals

Édition électronique

URL : http://journals.openedition.org/revdh/5830

DOI : $10.4000 /$ revdh. 5830

ISSN : 2264-179X

\section{Éditeur}

Centre de recherches et d'études sur les droits fondamentaux

\section{Référence électronique}

Sylvia Preuss-Laussinotte, "Premier rapport annuel de la Commission européenne », La Revue des droits de l'homme [En ligne], Actualités Droits-Libertés, mis en ligne le 31 mars 2011, consulté le 01 mai 2019. URL : http://journals.openedition.org/revdh/5830 ; DOI : 10.4000/revdh.5830

Ce document a été généré automatiquement le 1 mai 2019.

Tous droits réservés 


\title{
Premier rapport annuel de la Commission européenne
}

\author{
CHARTE DES DROITS FONDAMENTAUX DE L'UNION EUROPEENE
}

\author{
Sylvia Preuss-Laussinotte
}

1 Ce premier rapport fait le point sur les évolutions intervenues depuis 2010 en matière de droits fondamentaux dans le cadre des politiques de l'UE (p. 6 et svtes du rapport) : protection des données, accès à la justice, droits fondamentaux des Roms, promotion de l'égalité. Par ailleurs, la Commission européenne donne des pistes pour rendre effective l'application de la Charte des droits fondamentaux notamment pour les personnes. Rappelons que depuis l'entrée en vigueur du traité de Lisbonne, cette Charte a "même valeur juridique que les traités" (art. 6 du Traité sur l'Union européenne).

Elle indique notamment, ce qui pouvait sembler évident mais il était important qu'elle le précise : "Les autorités publiques des États membres (autorités législatives, exécutives et judiciaires) ne sont tenues de respecter la charte que lorsqu'elles mettent en cuvre le droit européen, notamment lorsqu'elles appliquent des règlements ou des décisions de l'UE ou transposent ses directives. Si une personne estime qu'une autorité nationale a violé la charte en mettant en cuvre le droit européen, elle peut saisir les juridictions nationales dans le pays en question. Sous la direction de la cour de justice, les juges nationaux sont compétents pour veiller au respect de la charte par les États membres lorsque ceux-ci mettent en oeuvre le droit de l'UE." La Commission ajoute que "les particuliers peuvent également porter plainte auprès de la Commission, qui a le pouvoir d'engager une procédure d'infraction contre l'État membre en question".

3 Cette position permet de donner des pistes au regard de l'éventuel "conflit" ou concurrence pouvant exister avec la CEDH - l'adhésion de l'UE à la CEDH prévue par le TUE étant en cours de négociation. Viviane Reding, vice-présidente et commissaire chargée de la justice qui s'était illustrée par sa position très critique à l'encontre de la France lors de l'expulsion de Roms, indique que «L'UE n'est pas un superflic des droits 
fondamentaux. La charte s'applique essentiellement aux institutions de l'UE, et c'est aux juges des États membres qu'il incombe au premier chef de veiller à leur application effective en vertu de leur propre constitution ». Et d'ajouter selon sa fermeté bien connue : «Il n'en demeure pas moins que, dans les cas où le droit de l'Union prévaut, je ne tolérerai aucune violation des droits fondamentaux ».

4 Rapport de la Commission européenne sur l'application de la charte des droits fondamentaux de l'Union européenne (30 mars 2011) - Communiqué de presse

\section{AUTEUR}

\section{SYLVIA PREUSS-LAUSSINOTTE}

Sylvia Preuss-Laussinotte est avocate 